\title{
Why Cash Transfers Are Good Policy in the COVID-19 Pandemic
}

\section{CENTER FOR QUANTITATIVE ECONOMIC RESEARCH}

\author{
CENTER FOR HUMAN \\ CAPITAL STUDIES
}

CENTER FOR FINANCIAL INNOVATION AND STABILITY

CENTER FOR HOUSING AND POLICY

\section{R. Anton Braun}

Federal Reserve Bank of Atlanta

\section{Daisuke lkeda}

Bank of Japan

\section{Summary:}

The COVID-19 pandemic has had an exceptionally large and negative impact on economic activity around the world. We show that cash transfers can be a useful policy tool during the pandemic. Cash transfers mitigate consumption inequality induced by the pandemic and provide incentives to individuals who are most negatively affected by lockdown policies to adhere to them.

\section{Key findings:}

1. Two important objectives of public policy during a pandemic are to induce social distancing by shutting down contact-intensive economic activities and mitigate the resulting surge in consumption inequality.

2. Cash transfers achieve both objectives for the COVID-19 pandemic. They encourage individuals with low savings to work less and shelter at home and also reduce consumption inequality.

JEL classification: E21, E62, H84

Key words: COVID-19 pandemic, cash transfers, stimulus payments, inequality

https://doi.org/10.29338/ph2020-04

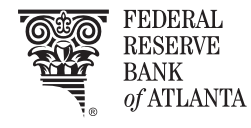

The Federal Reserve Bank of Atlanta's Policy Hub

leverages the expertise of Atlanta Fed economists and researchers to address issues of broad policy interest. Our research centers coordinate this work and seek to influence policy discussions. Areas of interest include: forecasting, fiscal policy, and macroeconomics (Center for Quantitative Economic Research); financial stability, innovation, and regulation (Center for Financial Innovation and Stability); human capital, labor markets, health, and education (Center for Human Capital Studies); and government-sponsored entity reform, mortgage markets, and affordable housing (Center for Housing and Policy). Sign up for email updates at frbatlanta. org/research/publications/policy-hub. 


\section{Why Cash Transfers Are Good Policy in the COVID-19 Pandemic}

\section{Summary:}

The COVID-19 pandemic has had an exceptionally large and negative impact on economic activity around the world. We show that cash transfers can be a useful policy tool during a pandemic. Cash transfers mitigate consumption inequality induced by the pandemic and provide incentives to individuals who are most negatively affected by lockdown policies to adhere to them.

\section{JEL classification: E21, E62, H84}

Key words: COVID-19 pandemic, cash transfers, stimulus payments, inequality

\section{About the Authors:}

R. Anton Braun is a research economist and senior adviser on the macroeconomics and monetary policy team in the Research Department at the Federal Reserve Bank of Atlanta. His major areas of study are macroeconomics and monetary policy.

Daisuke Ikeda is a senior economist and deputy head of Economic and Financial Studies Division in the Institute for Monetary and Economic Studies at the Bank of Japan. His major research fields are macroeconomics, monetary policy, and macroprudential policy.

Acknowledgments: The authors would like to thank Fumio Hayashi, Hirotaka Inoue, John Robertson, and Toshitaka Sekine for helpful comments. The views expressed here are the authors' and not necessarily those of the Federal Reserve Bank of Atlanta, the Federal Reserve System or the Bank of Japan. Any remaining errors are the authors' responsibility.

Comments to the authors are welcome at webmaster@atl.frb.org. 


\section{Introduction}

The COVID-19 pandemic has had an exceptionally large and negative impact on economic activity around the world. The objective of this article is to show that cash transfers can be a useful policy tool during the pandemic. Cash transfers mitigate consumption inequality induced by the pandemic, andfor those whom lockdown policies most negatively affect-they provide incentives to adhere to the policies.

When thinking about economic consequences and appropriate policy responses to a pandemic, it helps to compare pandemics with other natural disasters. A common feature of all natural disasters is that losses are idiosyncratic. If a tornado strikes your community, you might suffer injury, property losses, or both, but your next-door neighbor might escape unscathed. Natural disasters also reduce the productivity of work effort. Disruptions to power, roads, and transport make it harder for firms to produce the same amount of goods even if workers can show up to work. Such challenges in turn result in large declines in employment, output, and consumption. Economies cope with natural disasters such as tornados, earthquakes, hurricanes, and floods in two main ways. First, private insurance markets and government transfers mitigate ex post consumption inequality between those who experience a loss and those who do not. Secondly, efforts are made to restore the productive capacity in the region as quickly as possible.

Similar to typical natural disasters, the COVID-19 pandemic has been associated with sharp declines in employment, production, and consumption. In the United States, these declines started even before stay-at-home orders were imposed. ${ }^{1}$ As individuals became aware that working, traveling, and consuming in confined places with other people increased their infection risk, they started to reduce these activities. As in other natural disasters, a range of private arrangements and government policies have mitigated consumption differences between individuals who experience a loss directly via infection or indirectly due to changes in their employment situation. However, what is novel about pandemics is that public policies designed to maintain employment or get unemployed people back to work too quickly can increase infection and mortality rates and thereby compound the economic losses associated with the pandemic. Economists and epidemiologists agree that the best way to confront outbreaks of highly contagious and lethal viruses is to temporarily induce individuals to socially distance

\footnotetext{
${ }^{1}$ See Farboodi et al. (2020) for specific evidence from the United States.
} 
even if this means shutting down a large fraction of the economy (see, for example, Eichenbaum, Rebelo, and Trabandt 2020 and their references).

Policymakers have followed this advice mandating closures of schools and businesses and imposing shelter-at-home orders if they can and relying on moral suasion if mandates are ruled out. A premise of these containment policies is that many individuals, if left to their own, will not fully internalize the social consequences of a pandemic and continue undertaking contact-intensive work and consumption activities.

Containment policies increase the economic dislocations associated with the pandemic and further exacerbate consumption inequality because jobs in contact-intensive sectors tend to be relatively low paying. Policymakers have recognized this problem and have used a variety of tools to mitigate the surge in consumption inequality. Cash transfers from the government have been used extensively as a policy tool. In this article, we focus on their use in the United States and in Japan. Cash transfers can be a very effective policy tool during the pandemic. They help mitigate ex post consumption inequality and, in principle, are relatively easy to implement. In other natural disasters, cash transfers are less common because the policy objective is to provide incentives to people to get back to work as quickly as possible. Pandemics are different. Here, the short-term policy objective is to temporarily induce social distancing, and cash transfers also support this objective by incentivizing the workers who may be least likely to adhere to shutdown policies to reduce their labor supply.

We make these points using a simple model where age is used as a proxy for an individual's ability to weather a lockdown using their own liquid savings. Young individuals and families tend to have low levels of liquid assets, and workers in this situation may actually increase their labor supply during the pandemic because this is the only way to maintain their consumption levels. Younger individuals also face lower mortality risk from infection with the new coronavirus as compared to older individuals. These two factors mean that they are less likely to adhere to containment policies as compared to older workers who (on average) have higher levels of savings and face higher mortality risk. Finally, a rapid response is essential when dealing with the pandemic, and it is much quicker for a government to make cash transfers that depend only on an individual's residency status or age rather than the individual's income, employment status, or occupation. 
In the ensuing discussion, we document some facts about how earnings and wealth vary with age. Then, we use a model of the Japanese economy to illustrate how incentives to work vary with age during the pandemic. Finally, we use the model to show that cash transfers reduce ex post consumption inequality and also reduce the costs of adhering to containment policies.

\section{Labor Supply Incentives in a Pandemic}

A key financial incentive that influences an individual's labor supply decision during a pandemic is the individual's level of liquid savings net of debt. Liquid assets are a valuable resource in a pandemic because they can be used to support consumption if one gets laid off or if one wants to mitigate the risk of infection by working less and sheltering at home. Liquidity-constrained individuals-that is, people with low liquid savings and large financial commitments such as rents, mortgage payments, and credit card payments-lack this resource and consequently have only two ways to cope with a large decline in their earnings (resulting from fewer tips, lower sales commissions, or being laid off). First, they look for ways to minimize the decline in their earnings by working more hours or finding another job. Second, they cope with any remaining loss in their earnings by reducing consumption one for one with each dollar in lost earnings. Individuals with high levels of (net) liquid assets, in contrast, have the third option of drawing down their savings and thus are more likely to choose to reduce their labor supply when their wage is reduced or their risk of infection is high.

One group that is likely to be liquidity constrained is young individuals and families. Wolff (2017) reports that families with family head under 35 years of age had net liquid assets amounting to only 9 percent of the level held by the average American family in $2016 .^{2}$ One reason why young families are liquidity constrained is because their current earnings are well below their expected future earnings. Earnings increase with age between ages 20 and age 55 in the United States and between ages 20 and 50 in Japan (see charts 1 and 2). ${ }^{3}$

\footnotetext{
${ }^{2}$ This estimate is based on the Federal Reserve's 2016 Survey of Consumer Finances. Wolff's specific concept is mean financial resources, which is his notion of more net liquid assets. Wolff (2017) also estimates that total net worth for this age group is 9 percent of average net worth.

${ }^{3}$ The data for the United States is shown in the fourth quarter 2018 median usual weekly earnings report from the U.S. Bureau of Labor Statistics. The Japanese information is from the Japanese Ministry of Health, Labour and Welfare's average contractual cash earnings data from 2018.
} 


\section{Chart 1: Index of Earnings by Age in the U.S.}

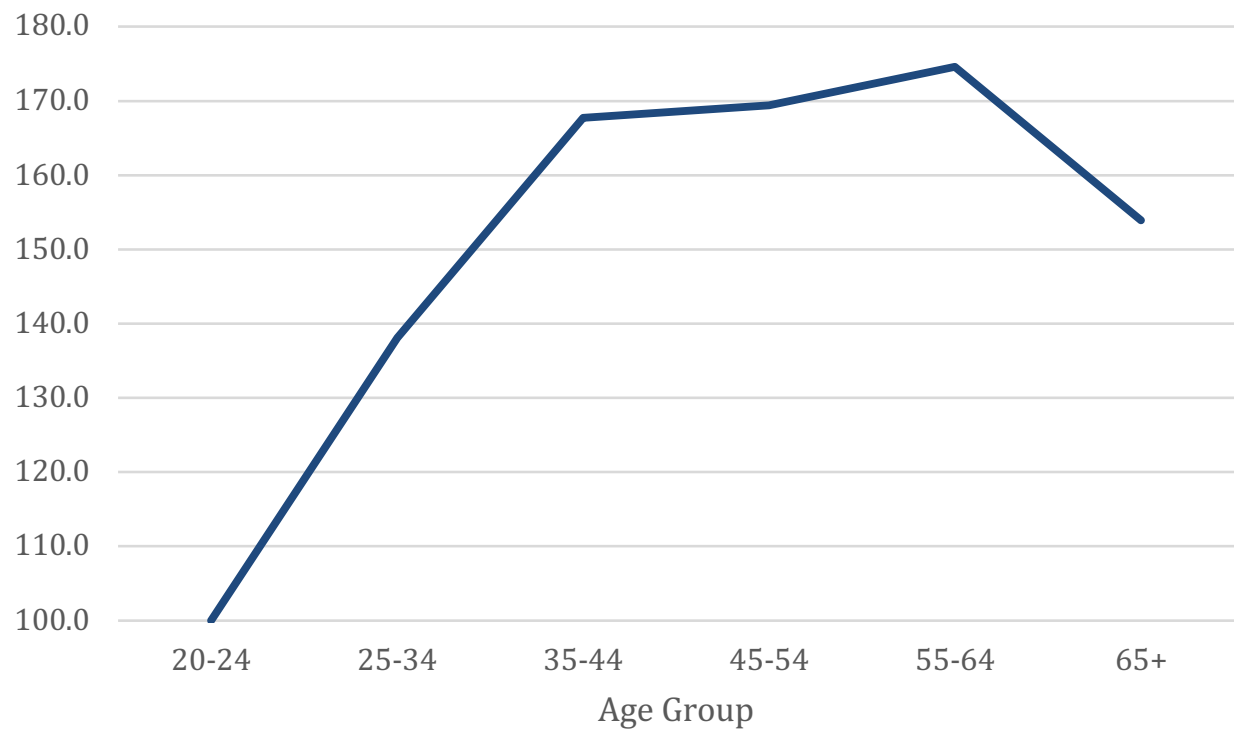

Source: U.S. Bureau of Labor Statistics median usual weekly earnings data, fourth quarter 2018

\section{Chart 2: Index of Median Earnings by Age in Japan.}

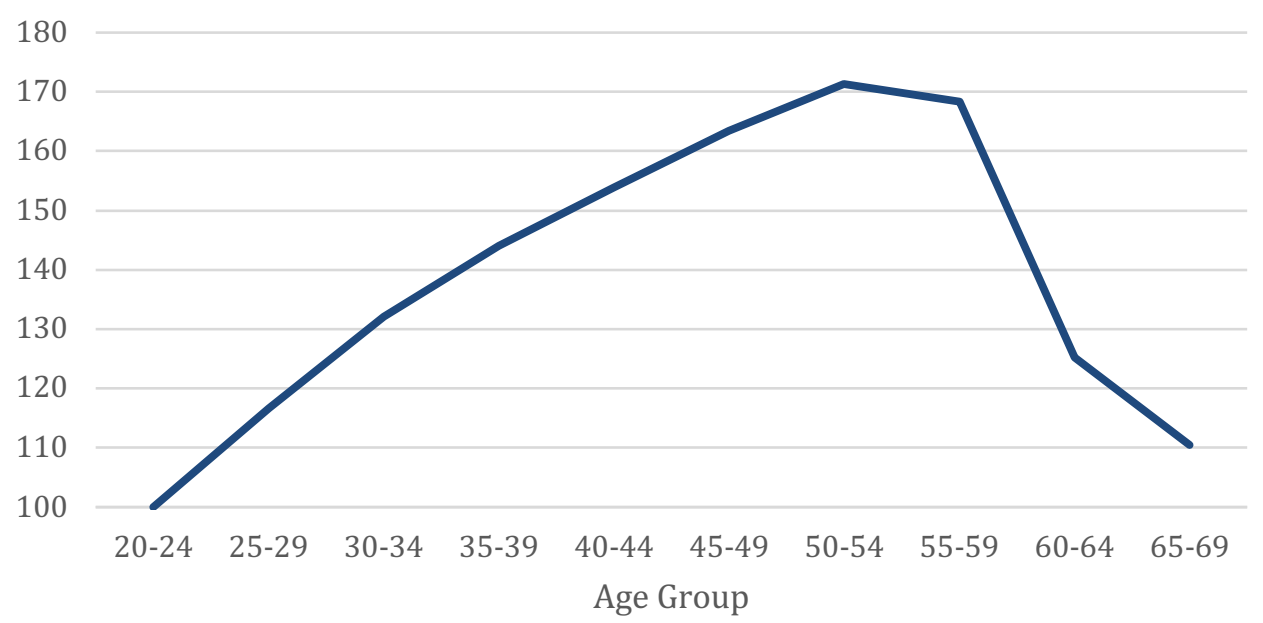

Ideally, younger workers would like to borrow against their higher future earnings to smooth their consumption over their lifetime. Younger workers often have high levels of student debt, mortgage payments, or both. During the 2008 financial crisis, American families under age 35 experienced the largest declines in net wealth (see Wolff 2017) and individuals under age 39 experienced the largest increase in transitions into serious delinquency (Federal Reserve Bank of New York 2018). It is already 
becoming clear that the COVID-19 pandemic will result in a bigger peak reduction in economic activity when compared to the 2008 financial crisis. Unfortunately, younger workers are not as well prepared. According to the 2016 Survey of Consumer Finances, median net worth of the same group of young households fell by 20 percent between 2007 and 2016.

The situation of young households is similar in Japan. Younger Japanese households have low levels of net financial assets and relatively high debt-to-income levels (Kitao and Yamada 2019), and they have become more vulnerable to economic shocks in recent years according to our calculations. ${ }^{4}$

Older workers in the United States and Japan are generally better prepared for even deep recessions. They have relatively higher earnings, higher net financial wealth, and more liquid assets. In addition, both countries have public pensions. Public pensions provide a stable flow of income that is particularly valuable to individuals who are close to retirement.

Concerns about becoming seriously ill or dying will induce individuals to socially distance to some extent even without any government intervention. Individuals who perceive a high risk will spend less time in contact-intensive commuting and work activities even if it means giving up part of their earnings. Individuals who feel that the risk is low might not adjust their behavior at all. Ferguson et al. (2020) estimate that the infection-fatality ratio for individuals aged $20-29$ is only 0.03 percent. The infection-fatality ratio then increases monotonically in age to 2.2 percent for individuals aged 60-69 and to 9.3 percent for individuals older than 79 . These estimates suggest that older workers are more likely to socially distance during the COVID-19 pandemic.

\section{Cash Transfers in the Pandemic}

We now use an empirical model to analyze the effect of cash transfers during the COVID-19 pandemic. To show their impact, we start by considering what happens when cash-transfers are absent. The first two columns of table 1 under the heading Baseline illustrate the response of hours worked by various age-groups to a lockdown shock using a life cycle model with young and old workers who make consumption, labor-supply, and saving decisions. ${ }^{5}$ The model is parameterized to reproduce some key

\footnotetext{
${ }^{4}$ For instance, using results reported in Kitao and Yamada (2019), we estimate that the fraction of households under age 35 with zero wealth increased from 8.1 percent in 2004 to 9.4 percent in 2014.

${ }^{5} \mathrm{We}$ model the lockdown shock as a requirement that firms reduce their utilization of capital and labor. The serial correlation on the shock is 0.2 . Workers in the model have children who vary with the age of the worker
} 
features of the Japanese macroeconomy, and the results correspond to a supply shock that reduces gross domestic product (GDP) by 5 percent in year 2020 and by 1.4 percent in 2021 (see columns 1 and 2 of table 2).

Table 1: Percentage Change in Hours Worked from Precrisis Levels by Five-year Age Groups to a Lockdown Shock in the Model

\begin{tabular}{c|cccccc} 
& Baseline & \multicolumn{2}{c}{$¥ 300,000$ Policy } & \multicolumn{2}{c}{$¥ 100,000$ Policy } \\
\hline year/age & 2020 & 2021 & 2020 & 2021 & 2020 & 2021 \\
\hline $21-25$ & 1.3 & 0.6 & -8.7 & 0.7 & -2.2 & 0.7 \\
$26-30$ & 0.5 & 0.5 & -6.3 & 0.6 & -2.0 & 0.6 \\
$31-35$ & -2.7 & 0.1 & -2.0 & 0.1 & -2.1 & 0.5 \\
$36-40$ & -2.7 & 0.1 & -1.8 & 0.2 & -2.3 & 0.3 \\
$41-45$ & -2.8 & 0.1 & -2.0 & 0.1 & -2.5 & 0.1 \\
$46-50$ & -2.9 & 0.0 & -2.1 & -0.1 & -2.7 & -0.2 \\
$51-55$ & -3.0 & -0.2 & -2.3 & -0.3 & -3.0 & -0.5 \\
$56-60$ & -3.4 & -0.5 & -2.7 & -0.6 & -3.6 & -1.0 \\
$61-65$ & -4.1 & -1.2 & -3.4 & -1.2 & -4.4 & -1.8 \\
\hline
\end{tabular}

Note: Variables are percentage changes from their precrisis level.

Table 1 reveals a large difference in the response of younger and older workers to the same shock. In the model individuals aged $21-29$ are liquidity constrained by assumption. ${ }^{6}$ They respond to a decline in their effective wages by working more. This response is why, in table 1, hours worked by the age group 21-25 increase by 1.3 percent and those by individuals in the 26-30 age group increase by 0.5 percent. Older workers have positive savings and choose to reduce hours worked instead.

The results in table 1 do not incorporate the negative effects of the pandemic on an individual's incentive to work because identifying its magnitude is difficult, given that lockdowns have also been imposed. But based on our previous discussion, we anticipate that the response of younger workers won't change much but that the declines in hours worked by older workers would be even larger than what we report here.

and the worker enters retirement at age 66. The interested reader is referred to Braun et al. (2009) and Braun and Joines (2014) for more details about the model and parameterization.

${ }^{6}$ Kaplan et al. (2014) use an empirical methodology to estimate the fraction of hand-to-mouth consumers in the United States, and Hara et al. (2016) apply the same methodology to Japan. Both studies find that the fraction of liquidity constrained households is highest in this age group. 
Table 2 reports some of the aggregate properties of the model. Aggregate labor input falls by 2.3 percent, and the public debt-to-GDP ratio rises by 0.7 percentage points. Notably, consumption inequality-which we measure by the cross-sectional standard deviation of consumption by ageincreases by 0.5 percent.

Table 2: Implications of a Lockdown Shock for Aggregate Economic Activity and Consumption Inequality in the Model

\begin{tabular}{l|rr|rrrr} 
& \multicolumn{2}{c}{ Baseline } & \multicolumn{3}{c}{$¥ 300,000$ Policy } & \multicolumn{3}{c}{$¥ 100,000$ Policy } \\
\hline Year/Variable & 2020 & 2021 & 2020 & 2021 & 2020 & 2021 \\
\hline GDP & -5.0 & -1.3 & -5.4 & -1.4 & -5.2 & -1.4 \\
Wages & -2.8 & -1.4 & -2.5 & -1.4 & -2.7 & -1.4 \\
Labor Input & -2.3 & 0.03 & -3.0 & 0.02 & -2.6 & 0.01 \\
Debt-to-GDP & 0.7 & 0.7 & 2.2 & 2.3 & 3.1 & 3.3 \\
Consumption & & & & & & \\
Inequality & 0.5 & -0.5 & -2.4 & -0.4 & -0.7 & -0.6 \\
\hline
\end{tabular}

Note: Variables are percentage changes from their precrisis level, except the public debt-to-GDP ratio, which reports the percentage point change.

As we explained above, pandemics are different from other natural disasters because working away from home during a pandemic has a negative external effect on other members of society. In Japan, many workers use trains and other public transit to get to work and many jobs involve close proximity with coworkers, customers, or both. ${ }^{7}$ These activities increase not only the risk of capturing the virus but also the risk of passing the virus to others. Thus, our result that young workers have incentivizes to work harder during the COVID-19 pandemic is troubling.

Concerns that some people would not fully internalize the benefits of social distancing have led policy makers to mandate lockdown policies. These policies have been particularly strict in China, where the government mandated the closure of most businesses in the city of Wuhan and used neighborhood committees to deliver food and make sure that all but essential workers sheltered at home. Shutdown policies in Europe have been less strict than China's but still robust with individuals facing fines for breaking shelter-at-home orders. The United States also mandated that businesses temporarily close or

\footnotetext{
${ }^{7}$ We do not have direct evidence on the nature of jobs held by young workers, but results in Mongey, Pilossoph, and Weinberger (2020) are suggestive. They find that liquidity-constrained individuals are more likely to work in contact intensive occupations.
} 
reduce the scope of their activities. Individuals have been ordered to shelter at home but rarely have faced any legal consequences if they don't. In contrast, Japan has relied exclusively on tools of social suasion instead, making requests that bars and restaurants close and urging people to shelter at home. ${ }^{8}$ Our results suggest that individuals aged 21-29 have the weakest incentives to respond to these requests. If they need to work away from home, they will likely do so because they are liquidity constrained, and working harder is the only way they can mitigate declines to their consumption during the pandemic.

Next let's consider the impact of cash-transfer policies. The first policy we consider is a 100,000 yen (about $\$ 1,000)$ transfer to residents of all ages including children. Results for this scenario are reported tables 1 and 2 (under the heading 100,000 yen policy). A cash transfer of 100,000 yen has a clearly discernible effect on work incentives of the young. Table 1 indicates that hours worked by individuals aged 21-30 fall, as do hours worked by individuals in the other age groups. The cash transfer is particularly valuable to younger workers because it relaxes their liquidity constraint and allows them to work less but still smooth their consumption through the crisis. Aggregate labor input and GDP now experience larger decline in table 2, because young workers are now working fewer hours.

The 100,000 yen cash-transfer policy also reduces consumption inequality. Consumption inequality in 2020 is now below its precrisis level. Younger workers benefit because they tend to be liquidity constrained. However, the transfer doesn't totally offset their earnings losses, and their consumption still declines. Another reason consumption inequality falls is because our model also has retirees, and older retirees are also liquidity constrained.

A final benefit of a 100,000 yen transfer scenario is its easy implementation. The only selection criterion is residency status, which is readily available in all town halls as a result of Japan's residencyregistration system. However, providing all residents with 100,000 yen cash transfers is relatively expensive from the perspective of the government adding 2.4 percentage points more to the government debt-to-GDP ratio in 2020 relative to the baseline scenario.

\footnotetext{
${ }^{8}$ Japan's pandemic law (the Act on Special Measures for Pandemic Influenza and New Infectious Diseases Preparedness and Response) does not give government officials the power to impose mandatory shelter-athome-directives.
} 
We have seen from the baseline scenario that young workers create the largest negative external effects, suggesting that a cash transfer targeting these individuals might have a larger (negative) effect on their work incentives at a smaller cost to the government. Results reported under the heading 300,000 yen policy in table 1 simulate a scenario where only workers under 36 years of age receive the cash transfer. From table 2, we see that the declines in hours worked by individuals age 30 and younger are much larger. This policy is also less expensive to the government, as the debt-to-GDP ratio only increases by 1.5 percentage points above the baseline scenario, and consumption inequality now falls by more than 2.4 percent. It is worth emphasizing that all individuals age 29 and below actually enjoy higher consumption than they did before the shock. However, this is not a problem as long as they consume from the safety of their home. Finally, this particular targeted transfer is also available in records at city halls and thus can be implemented as quickly as the transfer to all residents.

We have parameterized the model using Japanese data, but our main points are also relevant for the United States. The level of earnings for younger workers is similar in the two countries. Average salaries of Japanese in their twenties was $\$ 32,182$ in 2016 (DODA Annual Salary Survey). According to the U.S. Bureau of Labor Statistics, U.S. workers age 21-24 had median earnings of \$37,456 in 2016 and those age $25-34$ earned $\$ 39,416-$ so U.S. earnings were a bit higher. The age profile of earnings is also similar in the two countries (see charts 1 and 2), and the size of the stimulus checks in the Coronavirus Aid, Relief, and Economic Security (CARES) Act amounts to $\$ 3,400$ per family of four, which falls in the range of transfers that we have considered for Japan. One difference is that the CARES Act's stimulus checks are means-tested. It has taken more time to verify which recipients satisfy the income thresholds, and stimulus checks to some self-employed individuals have been delayed.

\section{Conclusion}

We have seen that pandemics are different from other natural disasters because the specific actions that mitigate mortality risk have a potentially large negative impact on the economy. Lockdown policies, when available, are quick and effective ways to induce social distancing. But by reducing economic activity, they also exacerbate consumption inequality. Cash transfers reduce consumption inequality and also help to induce young and other workers with low levels of liquid assets to stay home. We have seen that targeted cash transfers to displaced workers are attractive because they achieve these objectives at a relatively low cost to the government. Other targeted policies, such as temporary supplements to the level of unemployment compensation, offer similar benefits. Still, most targeted transfers require 
Federal Reserve Bank of Atlanta's Policy Hub • NO. 04-2020

significant amounts of time and resources to verify who qualifies. For this reason, residency-based cash transfers may be more effective in practice because they are quick-and acting quickly is important during any pandemic. 


\section{References}

Braun, R.A., D. Ikeda, and D.H. Joines. 2009. The saving rate in Japan: Why it has fallen and why it will remain low. International Economic Review 50: 291-321. https://doi.org/10.1111/i.14682354.2008.00531.x.

Braun, R.A., and D.H. Joines. 2015. The implications of a graying Japan for government policy. Journal of Economic Dynamics and Control 57: 1-23. https://doi.org/10.1016/i.jedc.2015.05.005.

Eichenbaum, M., S. Rebelo, and M. Trabandt. 2020. The macroeconomics of epidemics. National Bureau of Economic Research working paper no. 26882. https://doi.org/10.3386/w26882.

Federal Reserve Bank of New York. Third quarter 2018. Quarterly report on household debt and credit. Center for Microeconomics Data.

Farboodi, M., G. Jarosch, and M. Shimer. 2020. Internal and external effects of social distancing in a pandemic. National Bureau of Economic Research Working Paper no. 27059. https://doi.org/0.3386/w27059.

Ferguson, M., D. Laydon, G. Nedjati-Gilani, et al. 2020. Impact of non-pharmaceutical interventions (NPIs) to reduce COVID-19 mortality and healthcare demand. Imperial College of London report no. 16-0302020. https://doi.org/10.25561/77482.

Hara, R., T. Unayama, and J. Weidner. 2016. The wealthy hand to mouth in Japan. Economic Letters 141: 52-4. https://doi.org/10.1016/i.econlet.2016.01.011.

Kaplan, G., G. Violante, and J. Weidner. 2014. The wealthy hand-to-mouth. Brookings Papers On Economic Activity Spring 2014: 77-138. https://doi.org/10.1353/eca.2014.0002.

Kitao, S. and T. Yamada. 2019. Dimensions of inequality in Japan: Distributions of earnings, income and wealth between 1984 and 2014. Crawford School of Public Policy's Centre for Applied Macroeconomic Analysis working paper no. 2019-36. Australian National University

Mongey, S., L. Pilossoph, and A. Weinberger. 2020. Which workers bear the burden of social distancing? Unpublished manuscript, University of Chicago.

Wolff, E. 2017. Household wealth trends in the United States, 1962 to 2016: Has middle class wealth recovered?" National Bureau of Economic Research working paper no. 24085, November. https://doi.org/10.3386/w24085. 